\title{
ASÍ EN LA COCINA COMO EN LA FÁBRICA
}

\author{
JUAN BRAVO BRAVO \\ Universitat Politècnica de València
}

Recibido 09/02/2011

Aceptado 20/05/2011

\section{Resumen}

Estudio de un caso: definición, desarrollo y crisis del tipo de cocina doméstica contemporáneo en Europa. Se recurre a interpretaciones de género, actualmente muy fructíferas en el ámbito de la Historia del Diseño. La cocina de la Haus am Horn en la Exposición Bauhaus de Weimar, 1923. La Cocina de Frankfurt diseñada por Grete Schütte-Lihotzky, 1927. Propuestas de comunas y cocinas colectivas. Identificación de sus debilidades para dar respuesta a las actuales características de la sociedad del bienestar y planteamiento de su capacidad para contribuir al incompleto proceso de igualdad de género, estimulando la sociabilidad y corresponsabilidad del grupo familiar en las tareas domésticas.

Palabras clave: Historia del diseño; espacio doméstico; tipologías de cocina; estudios de género

\begin{abstract}
Case study: definition, development and crisis of contemporary home kitchen in Europe. The paper draws on gender interpretations currently successful in History of Design. The Haus am Horn kitchen in the Exhibition Bauhaus, Weimar, 1923. The Frankfurt Kitchen designed by Grete Schütte-Lihotzky in 1927. Proposals for communes and collective kitchens. Identifying weaknesses in response to the current characteristics of the welfare society. Approach to their capacity to contribute to the incompleteness of gender equality process by encouraging the sociability and responsibility in household chores.
\end{abstract}

Keywords: History of Design; domestic space; kitchen types; gender studies 


\section{Diseño en femenino. Estudio de un caso: la cocina doméstica}

No ha sido hasta las últimas décadas, con la proliferación de las enseñanzas de diseño en sus diferentes variantes, cuando la Historia del Diseño ha ido configurándose como una disciplina autónoma. Sus orígenes se remontan a los años treinta del siglo $\mathrm{xx}^{1} \mathrm{e}$ inicialmente se nutrió de métodos e interpretaciones procedentes de la historia del arte en general y de la arquitectura y de las artes decorativas en particular, disciplinas con las que se entronca, si bien, progresivamente ha ido enriqueciéndose con aportaciones procedentes de otras ciencias como la antropología, la sociología o la arqueología, que han ido aportándole nuevas e ilustrativas perspectivas desde las que contemplar su objeto de estudio. De esta manera, a los estudios iniciales relativos a las relaciones entre forma, función y producción, y centrados en la labor pionera de una serie de arquitectos y artistas heroicos, se ha ido añadiendo un conjunto cada vez más numeroso de obras dedicadas a estudiar el fenómeno del diseño desde nuevos aspectos como, por ejemplo, el desarrollo de la profesión; sus relaciones con el contexto socio-político; los vínculos entre diseño, publicidad y consumo; o el papel de la mujer en el diseño.

Probablemente ha sido la última de esas nuevas miradas anteriormente mencionadas la que se ha revelado como una de las más fructíferas, al constituirse en una especie de reflejo de la totalidad puesto que, a su vez, ha ramificado sus aportaciones en diferentes direcciones: desde la recuperación de las primeras mujeres diseñadoras; pasando por el análisis del rol de consumidora, tradicionalmente asignado a las mujeres en las sociedades capitalistas, y su responsabilidad en la definición de algunas características de la identidad femenina; hasta una crítica específica a algunas aportaciones del Movimiento Moderno al poner de relieve cómo éste, al entronizar la máquina, resalta aspectos vinculados con la ciencia, la tecnología o la producción industrial -habitualmente identificados con el universo masculino-, para relegar a un

1. Fue en esa década cuando apareció la primera literatura específica: Herbert READ: Art and industry, the principles of industrial design. Londres: Faber\&Faber, 1934; ó Nikolaus PEVSNER: Pioneers of the modern movement, from William Morris to Walter Gropius. Londres: Faber\&Faber, 1936. 
segundo plano aquellos otros -tradicionalmente relacionados con lo femenino-, como son la esfera de lo doméstico, lo privado o lo decorativo. ${ }^{2}$

El presente texto pretende conjugar, en cierta manera, varias de esas opciones a través del estudio de un caso concreto: el proceso de definición, difusión y crisis de la cocina doméstica moderna. Con este propósito, empieza por repasar la aparición y el desarrollo del tipo de cocina contemporánea, resaltando la significativa aportación de arquitectas y diseñadoras pioneras en la definición de muchas de cuyas características todavía permanecen vigentes en la actualidad. En segundo lugar, se señala el mayoritario rol de usuarias y consumidoras habitualmente asignado a la mujer en la consolidación del nuevo espacio así definido, para plantearse la manera en que esos nuevos diseños de cocina han contribuido a la progresiva emancipación de la mujer cuestionándose su validez actual y en qué direcciones deberían evolucionar para impulsar el todavía incompleto proceso de igualdad de género en las sociedades post-industriales contemporáneas.

\section{Mujer y Bauhaus: Benita OTTE y la cocina de la Haus am Horn, Weimar,} 1923

Como en tantos otros aspectos relativos al diseño industrial, los orígenes de la cocina moderna pueden rastrearse también en el trabajo de la Bauhaus, la escuela vanguardista y democrática por excelencia.

Es conocido cómo la Primera Guerra Mundial contribuyó a la modernización de determinados aspectos sociales, facilitando el acceso de buen número de mujeres a las instituciones de enseñanza así como que muchas otras alcanzaran una cierta independencia económica como resultado de ocupar aquellos puestos laborales que sus compatriotas masculinos habían dejado vacantes tras su incorporación a los frentes de batalla. Una vez finalizada la Guerra, la constitución de la República de Weimar garantizó, por primera vez, el derecho de las mujeres a estudiar y a votar, reconociéndoles una igualdad de derechos que, de la misma manera, fue explícitamente recogida en el primer programa de la Staatliches Bauhaus de 1919. Sin embargo, la

2. Para ampliar estas cuestiones relativas a la historiografía del diseño, véase Judy ATTFIELD: «Form/female follows Function/male: Feminist Critiques of Design», pp. 199-225, en John A. WALKer: Design history and the history of design. Chicago: Pluto Press, 1989 y, en español, Isabel CAMPí: «Algunas reflexiones sobre la historia del diseño de productos», pp. 219-241, en La idea y la materia, V. I: El diseño de producto en sus orígenes. Barcelona: Gustavo Gili, 2007. 
desmovilización obligó a un retroceso en muchos de estos aspectos. ${ }^{3}$ En ese mismo sentido, investigaciones recientes están poniendo de relieve cómo pese a que, en teoría, aquellos alumnos que superaban el curso inicial o Vorkurs tenían libertad para elegir el taller donde querían completar su formación, de forma más o menos implícita, se obstaculizó la incorporación de la mujer a los talleres mecánicos -tradicionalmente considerados como masculinos-, para orientarla principalmente hacia aquellos otros de carácter artesanal -habitualmente relacionados con lo femenino- como eran el textil, el de cerámica o el de encuadernación. ${ }^{4}$ Aún así, el sistema había dejado de ser impermeable a la incorporación femenina por lo que, entre los diseñadores más activos y reconocidos, se encuentran algunas mujeres cuya obra posee incuestionable calidad, como son los casos de Marianne Brandt, Gunta Stölzl o Anni Albers, por citar sólo algunos ejemplos relevantes. En esa misma línea, cuando con ocasión de los primeros egresados de la Escuela, en 1923, se organizaron una serie de actos destinados a justificar la subvención que ésta recibía del estado de Turingia, uno de los logros que recibió un reconocimiento más unánime había sido también diseñado por una mujer.

Con el doble objetivo de satisfacer a las autoridades estatales y de difundir las actividades de la Escuela entre arquitectos, artistas y críticos alemanes y extranjeros que habían sido convenientemente convocados, se programaron diferentes conferencias, conciertos, obras de teatro y exposiciones. La más ambiciosa de éstas últimas consistió en la construcción de una vivienda unifamiliar, la Haus am Horn, inicialmente denominada Casa Modelo y, más tarde, Casa Experimental. El proyecto de la misma se debió al joven profesor de pintura Georg Muche y fue democráticamente elegido por los alumnos de la Escuela entre las diferentes opciones presentadas. La ejecución de la obra fue dirigida por el estudio de Walter Gropius, que había aceptado deportivamente el rechazo de su propia propuesta, mientras que en su equipamiento participaron todos los talleres de la escuela aportando prototipos de sus diseños.

3. Sobre los cambios sociales y los nuevos roles de género en la República de Weimar, puede verse Eric D. Weitz: La Alemania de Weimar. Presagio y tragedia. Madrid: Turner, 2009, especialmente el capítulo titulado «Cuerpos y sexo», pp. 345-383.

4. Véase, por ejemplo, Magdalena Drosde: Bauhaus 1919-1933. Colonia: Taschen, 1991, en particular: «Mujeres en la Bauhaus», p.40; Anja BAUMHOFF: «Las mujeres en la Bauhaus: un mito de la emancipación», pp. 96-107, en Jeannine FIEDLER y Peter FEIERABEND (eds.): Bauhaus. Madrid: Könemann, 2000; ó, también, Mercedes VAlDiviESO: «Retrato de grupo con una dama: el papel de la mujer en la Bauhaus», pp. 246-255, en Anna CALVERA y Miquel MALlol (eds.): Historiar desde la periferia: historia e historias del diseño. Barcelona: Universitat de Barcelona, 2001. 
Se trata de una vivienda aislada de una sola planta cuadrada $(12,70 \mathrm{x}$ $12,70 \mathrm{~m}$ ), lo que arroja una superficie construida de unos $160 \mathrm{~m}^{2}$, a los que hay que sumar otros $60 \mathrm{~m}^{2}$ adicionales en sótano, donde se encuentran diferentes dependencias de servicio, tales como la lavandería, la caldera de calefacción o un almacén. En el centro se sitúa la pieza colectiva más importante de la vivienda: la sala de estar, de planta también cuadrada (5,94 x 5,94 m) con una altura $(4,10 \mathrm{~m})$ superior en más de metro y medio a la del resto de la casa, para poder abrirse así a la iluminación y ventilación directa mediante una serie de ventanas altas que orlan su perímetro. Alrededor de esta pieza central se organizan -de acuerdo con criterios funcionales o de orientaciónel resto de estancias de la vivienda, reduciendo al mínimo los espacios de distribución, según un esquema tipológico similar al de las viviendas-patio romanas, planificadas alrededor de un patio descubierto -el atrio-, cuyo lugar está aquí ocupado por ese mencionado salón, cubierto a mayor altura.

Tanto la vivienda como su equipamiento fueron objeto de críticas poco favorables desde diferentes frentes. Aquéllos situados en posiciones antivanguardistas, declaradamente contrarias a la Escuela, la tacharon de mal gusto, censurando su ascetismo exterior, la ausencia de cuarto de servicio o rechazando la evidente inspiración técnica y mecánica de buena parte su equipamiento. Por su parte, desde más favorables posturas de vanguardia -casos de Adolf Behne o Ernst May, por ejemplo-, se criticó que estuviera destinada a un tipo de usuario socialmente minoritario, bien distinto de aquel que constituía el verdadero problema social del momento -la vivienda mínima-, consagrando tanto una forma de vida familiar patriarcal como unos estándares superficiales muy alejados de los convenientes para ese caso. Desde el punto de vista formal criticaron también el excesivo estatismo y rigidez geométrica de su proyecto arquitectónico así como la evidente deuda de su mobiliario con los diseños de Rietveld. ${ }^{5}$

La cocina, sin embargo, suscitó opiniones casi unánimemente favorables, para alcanzar posteriormente su reconocimiento como prototipo europeo de cocina moderna. Su proyecto se debía a Ernst Gebhardt y Benita Otte quien, como la mayoría de las estudiantes de la Bauhaus, estaba adscrita al taller textil y no al de mobiliario. Había sido diseñada aplicando criterios de

\footnotetext{
5. La vivienda que, en 1996, fue declarada por la UNESCO monumento de la humanidad, puede visitarse en la actualidad tras su conveniente restauración. Una minuciosa descripción de la misma, así como de las vicisitudes que rodearon su construcción y primera exhibición, puede encontrarse en Mercedes VALDIVIESO: «La aportación de la Bauhaus a la innovación del espacio doméstico: la «Casa Modelo» Haus am Horn (1923)», <http:// www.ub.edu/gracmon/capapers/mercedesvaldivieso.pdf>, consultado el 05-12-2010.
} 


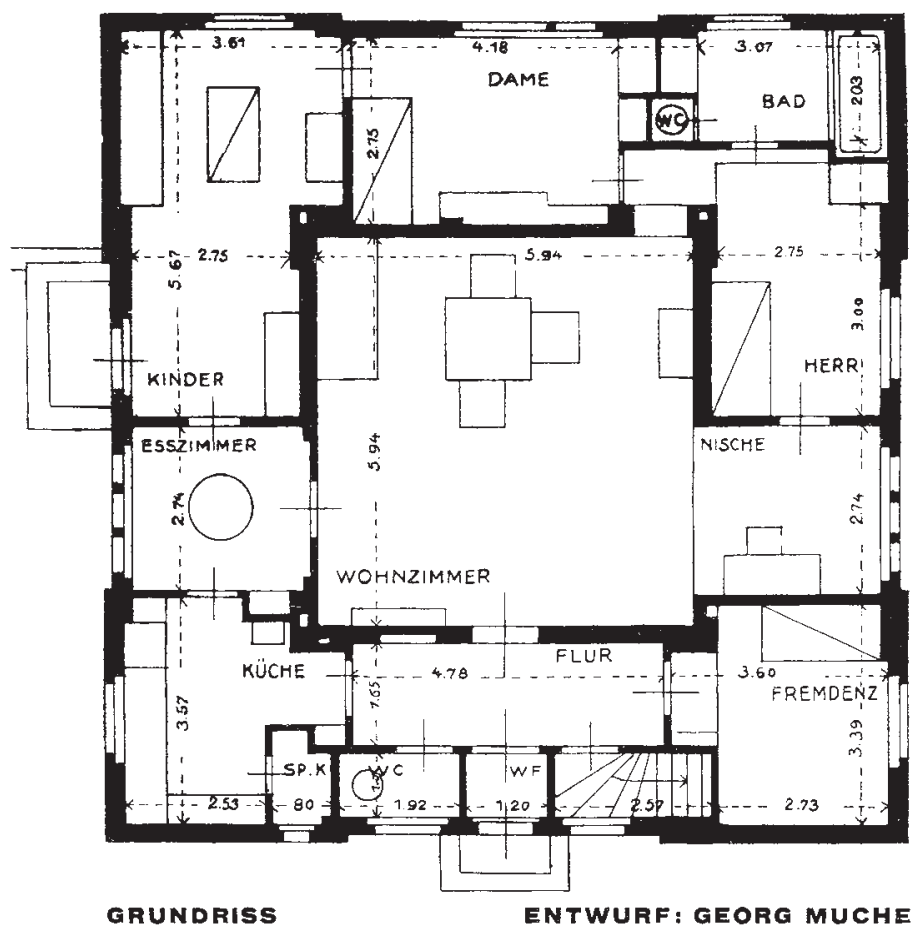

Georg Muche: Casa Modelo Exposición Bauhaus, Weimar, 1923. Planta general.

racionalización del espacio para facilitar el trabajo de un ama de casa que carecía de servicio doméstico.

La cocina habitual en esos años estaba comúnmente equipada mediante una serie de aparadores para el almacenamiento de alimentos y menaje junto a alguna que otra mesa donde realizar las tareas de limpieza y preparación, todo ello dispuesto en yuxtaposición a los tres elementos funcionales fundamentales: la cocina, el fregadero y, en su caso, la nevera. Por el contrario, en esta ocasión se avanza claramente hacia un tipo de cocina compacta e integrada, compuesta por dos clases distintas de armarios -murales y de base-, que se disponen adosados a las paredes según una configuración en L, para definir una superficie de trabajo continua y sin juntas al mismo nivel que el fregadero y los fogones. Pese a que su altura era adecuada para trabajar de pie, se liberó parte del espacio inferior para las piernas y donde integrar un taburete que permitía sentarse para realizar determinadas tareas con mayor comodidad. Sobre dicha superficie de trabajo se abrió una amplia ventana basculante para procurar un adecuado nivel de iluminación y ventilación 


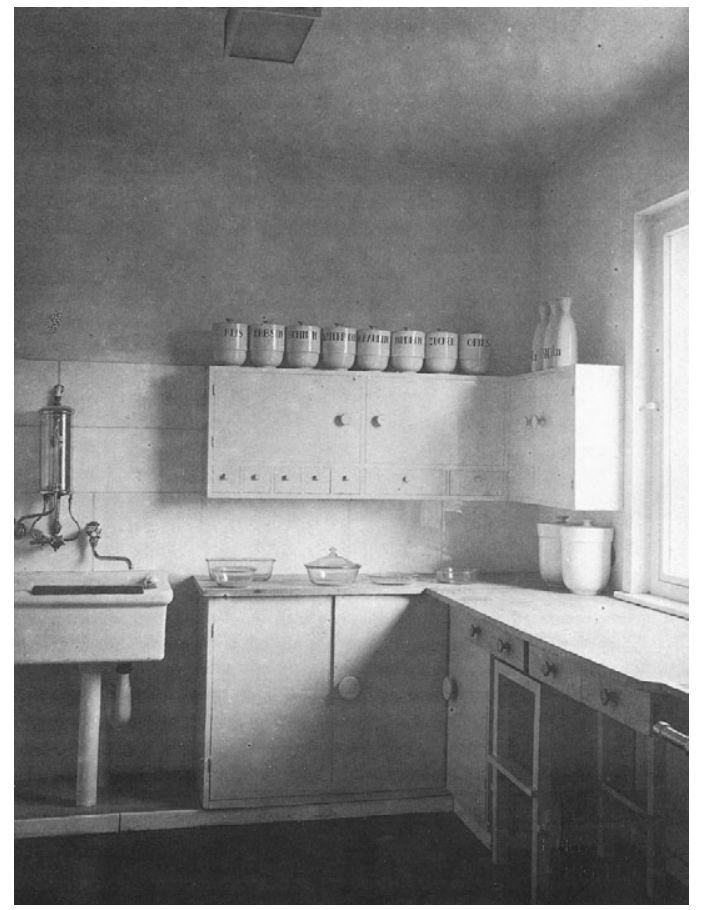

Benita Otte y Ernst GebHardt: Cocina de la Casa Modelo, Weimar, 1923. Vista.

natural sin interferir las actividades que se realicen sobre ella. Para facilitar las tareas de limpieza y mantenimiento, los armarios de base carecen de patas que han sido sustituidas por un zócalo continuo, al tiempo que las paredes se han revestido parcialmente mediante piezas cerámicas vidriadas. En palabras de Sigfried Giedion, quien también se contaba entre los visitantes invitados por Walter Gropius:

Su punto de partida era el centro de almacenaje; un sencillo fregadero y una alacena quedaban situados junto a la pared larga, con la alacena dividida ya en dos elementos, el armario de base y el armario de pared. El espacio de la ventana es plenamente utilizado y recuerda las cocinas americanas Craftsman de 1910. Una amplia superficie de trabajo discurre por debajo de la ventana oscilante y al nivel de la misma se extiende la parte superior de la cocina de gas, alargada a su vez por una superficie como la que aparecería en las cocinas americanas alrededor de los años treinta. ${ }^{6}$

6. Sigfried Giedion: La mecanización toma el mando. Barcelona: Gustavo Gili, 1978, p. 529. El autor se centra fundamentalmente en las aportaciones estadounidenses, alguna de las cuales será comentada más adelante. 
Por otro lado, cabe señalar también que en el debate arquitectónico de la época se estaba discutiendo sobre las ventajas e inconvenientes entre una cocinalaboratorio, exclusivamente dedicada a las tareas culinarias, y una cocinacomedor, destinada no solo a la manipulación de los alimentos sino también a su ingesta. La primera tenía como ventaja la facilidad para aislar el resto de la vivienda de las molestias derivadas de la cocina: humos, olores, suciedad, etc. y como inconveniente el alargamiento de los recorridos de servicio y una mayor dificultad para atender a los niños mientras uno se ocupaba en las tareas domésticas.

En el caso de la Haus am Horn se ensayó una opción de cierto compromiso dado que, por un lado, se trata de una estancia de trabajo en exclusiva pero, por otro, se encuentra adyacente al comedor y únicamente separada de éste por una puerta que permite aislarla o comunicarla a conveniencia. Además, dicha puerta se encuentra enfilada con la correspondiente al cuarto infantil -destinado a dormitorio y juegos- que se abre, simétricamente a la cocina, al otro lado del comedor. Esta solución permite vigilarlos al tiempo que los mantiene alejados de los riesgos inherentes a la inevitable presencia en la cocina de fuego y agua. $^{7}$

El prototipo de cocina diseñado por Benita Otte para la Bauhaus tuvo continuidad pocos años después cuando, aprovechando el breve alivio para la economía alemana que supuso el Plan Dawes, entre la hiperinflación de 1923 y las consecuencias de la gran depresión de 1929, el Werkbund organizó en 1927 la exposición de Stuttgart. Como es conocido, el acontecimiento principal estuvo constituido por la construcción de la Weissenhofsiedlung, bajo la dirección de Mies van der Rohe y con participación de algunos de los arquitectos de vanguardia más relevantes de la época, tanto alemanes como extranjeros. Pero, en paralelo, se celebró también una segunda exposición dedicada al equipamiento doméstico bajo el título de Die Wohnung (El apartamento), dirigida por Lilly Reich, ${ }^{8}$ en la que la organización de la cocina constituía

7. Según Mercedes VALDivieso: op. cit., n. 29, esa posición del cuarto infantil se tomó a última hora, dado que en los planos iniciales, fechados a principios de 1923, éste se encontraba situado en la esquina orientada a sur, ocupada en la solución final por el baño y el dormitorio masculino.

8. A partir de esta exposición, Lilly Reich empezaría una fructífera colaboración con Mies van der Rohe que se prologaría hasta el exilio de éste en EUA en 1938. Durante ese período participaron en la Exposición de Barcelona de 1929 y en la de Berlín de 1931. En 1932, un año antes del cierre de la Escuela, Reich llegó a dirigir el taller de interiorismo y diseño textil de la Bauhaus, en sustitución de Gunta Stölzl. Sobre su vida y obra puede verse, en español, Carmen ESPEGEl AlONSO: Heroínas del espacio: mujeres arquitectos en el movimiento moderno. Buenos Aires: Atlántida, Nobuko, 2007, pp. 134-163. 
cocina diseñada por Erna Meyer, asesora de la exposición Weissenhof de 1927.

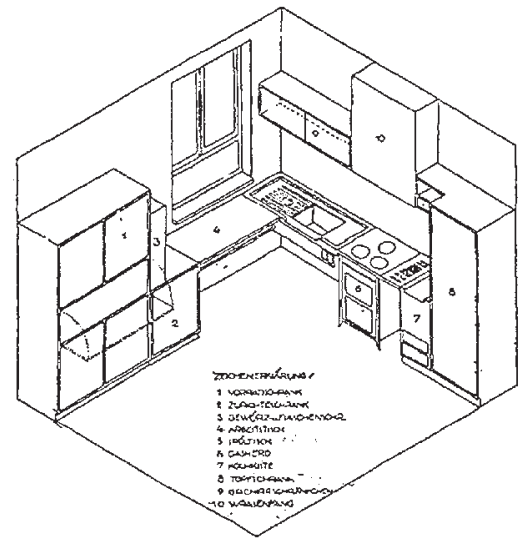

cocina de J.J. P. Oud para la exposición. Weissenhof, 1927.

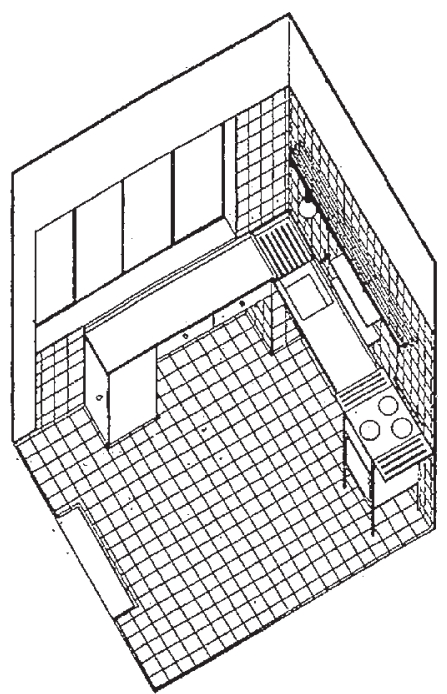

Jacobus J. P. OUD: Vivienda unifamiliar, Weissenhofsiedlung, Stuttgart, 1927. Planta y vista.

uno de sus temas más significativos. Las encargadas del mismo fueron Hilde Zimmermann y Erna Meyer quien también se había ocupado en asesorar a los arquitectos participantes en todos aquellos requisitos que debían cumplir las cocinas de las viviendas por ellos proyectadas para la Weissenhof. No en vano se trataba de la autora de Der neue Haushalt (El nuevo hogar), texto de gran influencia publicado por vez primera en 1926 y continuamente reeditado hasta 1941. Entre otras características, esta diseñadora fue la primera en incorporar criterios de ergonomía en el proyecto de cocinas para dimensionar, por ejemplo, la altura correcta para trabajar de pie o qué tipo de tareas podían realizarse desde un asiento.

En opinión de Erna Meyer, el mejor diseño de cocina entre todos los participantes en la Weissenhof correspondió a las viviendas construidas por el arquitecto holandés Johanes J. P. Oud. Éste insistió en una cocina integrada y compacta dispuesta en L, con la superficie de trabajo perfectamente iluminada y ventilada bajo una amplia ventana y liberando parte del espacio inferior para las piernas -lo que permite sentarse para trabajar con mayor comodidad-; los armarios murales han sido sustituidos, en esta ocasión, por meros estantes y 
una barra donde tener a mano parte del menaje y de los accesorios necesarios para las diferentes tareas. Sin embargo, la aportación más interesante de Oud fue quizás la apertura de una ventana interior con carpintería corredera que comunicaba la cocina con el salón-comedor adyacente, estableciendo de esta forma no solo un vínculo directo -a modo de pasaplatos- para facilitar el servicio de la mesa, sino también una comunicación visual y auditiva que suaviza el aislamiento de la cocina -y de la cocinera- como espacio exclusivamente de trabajo.

\section{Grete Schütte-Lihotzky y la definición del tipo de cocina contemporánea}

A diferencia de los ejemplos anteriores, que permanecieron como experiencias aisladas, el caso que tuvo una mayor repercusión, hasta el punto de configurarse como tipo de referencia, es el conocido como Frankfurter Küche o Cocina de Frankfurt. Este modelo se asumió como estándar en la ambiciosa operación de construcción de viviendas sociales que, de manera similar a otras ciudades europeas tales como Berlín, Rótterdam o Viena por ejemplo, se acometió en dicha ciudad durante el período de entreguerras. Cuando, en 1924, el liberal Ludwig Landmann accedió a la alcaldía de Frankfurt, nombró al arquitecto Ernst May al frente del Departamento de Construcciones de la ciudad, estructura administrativa de nueva creación que unificaba diferentes departamentos relacionados con la construcción y promoción de viviendas, lo que le proporcionó un amplio margen de acción para enfrentarse con éxito a ese acuciante problema de carestía de viviendas, común a numerosas ciudades europeas tras la Primera Guerra Mundial.

Ernst May convocó a su alrededor a un nutrido grupo de colaboradores, alemanes y extranjeros, procedentes de diferentes disciplinas. Entre ellos se encontraban, por ejemplo, el arquitecto Eugen Kaufmann, responsable del departamento de estandarización; los diseñadores Hans Leistikow, gráfico, y Ferdinand Kramer, de mobiliario -que había seguido un año de formación en Bauhaus-; o la arquitecta austriaca Grete Schütte-Lihotzky, ${ }^{9}$ que se hizo cargo

9. Margarete SCHÜTTE-LinotZKY (1897-2000) fue la primera arquitecta austriaca y una de las primeras de Europa. Formada en Viena entre 1915-19 con Oskar Strnad, Heinrich Tessenow o Josef Hoffmann, colaboró con Adolf Loos antes de integrarse en el equipo de Ernst May en Frankfurt, dedicando toda su vida a la arquitectura desde posiciones política y socialmente comprometidas. Dicho compromiso le condujo al exilio — junto a May y otros miembros de su equipo- primero en la URSS, donde trabajó entre 1930 y 1937 como profesional y docente, y más tarde en Turquía entre 1938-40. Como integrante de la resistencia antifascista volvió a Viena durante la Guerra donde fue apresada por los nazis y, aunque pudo escapar de la pena de muerte, pasó en prisión desde 1941 hasta el final de la contienda en 1945. Sobre su vida y obra puede verse Angela 
de la investigación y planificación para el equipamiento de las nuevas cocinas. El modelo desarrollado por Schütte-Lihotzky fue instalado en más de 10.000 viviendas construidas en Frankfurt entre 1924-1930 alcanzando también cierta resonancia internacional, de modo que, por ejemplo, el ministro de trabajo francés Louis Loucheur proyectó para su país 260.000 viviendas sociales equipadas con este diseño de cocina. ${ }^{10}$ En palabras de la propia Grete SchütteLihotzky, las responsabilidades que hubo de asumir fueron las siguientes:

En primer lugar, mi trabajo consistió en considerar los principios básicos envueltos en el planteamiento y construcción de viviendas, con vistas a racionalizar la organización doméstica. ¿Dónde vivir, cocinar, comer y dormir? Esas son las cuatro funciones básicas que toda vivienda debe cubrir. La función básica, que influye en el diseño de manera decisiva, es cocinar y comer. Mi primera propuesta, construir un salón y combinar una cocina y comedor, fue rechazada bajo el argumento del coste [...] Así que nos decidimos por una sola unidad, compuesta de una cocina compacta e integrada, separada del salón-comedor mediante una amplia puerta corredera. Consideramos la cocina como una especie de laboratorio que, a causa del mucho tiempo que pasamos en ella, tiene que ser «hogareña». El tiempo necesario para ejecutar las diferentes funciones fue medido usando un cronómetro, como en el sistema de Taylor, con el objetivo de alcanzar la óptima y ergonómica organización del espacio. ${ }^{11}$

Dos son los aspectos destacables en la cita anterior. En primer lugar la revelación que la propia arquitecta hace de alguna de las referencias metodológicas que influyeron en su tarea al citar el sistema de Taylor. Remite a los esfuerzos que, durante la década de 1910, Christine Frederick (casada con Frederic W. Taylor) había estado realizando para trasladar al espacio doméstico las teorías sobre optimización productiva -de tiempos y movimientos- que, junto a su esposo, estaba desarrollando y aplicando con tanto éxito a diferentes cadenas de montaje estadounidenses de producción industrial. En The New Housekeeping (La nueva gestión doméstica), publicado en 1913, Christine Frederick analiza científicamente una cocina sin servicio doméstico e incluye unos

OEDEKOVEN-GERISCHER et al. (eds.): Frauen im Design: Berufsbilder und Lebenswege seit 1900. Women in Design: Careers and Life Histories since 1900 (2 v.) Stuttgart: Design Center Stuttgart, 1989, pp. 148-173 y, en español, Carmen EsPEGEl AlONSO: Op. cit., pp. 165-195.

10. Rita Mielke: La cocina. Historia, cultura, diseño. Berlín: Feierabend, 2004, p. 19

11. Grete SCHÜTTE-LihotZKY: Erinnerungen (Memorias). Viena: manuscrito inédito, 198090. Citado en la web del Museo Austriaco de Artes Aplicadas y Arte Contemporáneo (MAT) que, desde 1989-90 expone una réplica de la cocina realizada por el arquitecto Gerhard Lindner en colaboración con la propia Grete. Véase <http://www.mak.at/e/ sammlung/studien/studiens_frakue_e.html>, consultada el 06-12-2010 (traducción propia de la versión en inglés). 

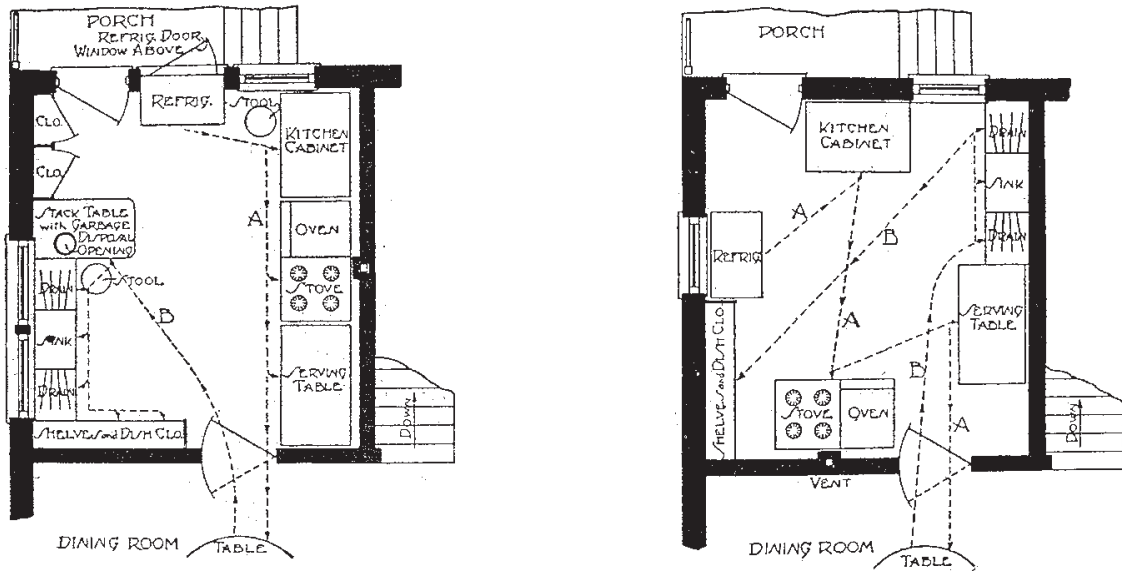

Christine FredericK: The New Housekeeping, 1913. Diagramas de cocina ineficaz y eficaz.

diagramas comparativos entre los movimientos realizados por el ama de casa durante su proceso de trabajo en lo que la autora denomina «cocina ineficaz» y en una cocina donde se ha racionalizado la disposición de sus diferentes elementos y calificada, por tanto, de «eficaz». Otro de sus textos, Scientific Management in the Home (Gestión cientifica del hogar), fue traducido con gran éxito al alemán en 1922 y está, sin duda, en la base del libro de Erna Meyer Der neue Haushalt (El nuevo hogar) de 1926, anteriormente citado como obra de referencia a la hora de materializar ejemplos como los de Johannes J. P. Oud en la Weissenhof de Stuttgart de 1927, así como de sus contemporáneos berlineses de Bruno Taut.

La aportación estadounidense tiene raíces incluso anteriores, en la obra de las hermanas Catherine Beecher y Harriet Beecher-Stowe que, ya en 1869, habían publicado The American Woman's Home (El hogar de la mujer americana), texto que incluye unos bocetos de cocina donde es posible detectar el embrión de algunas características que desarrollarán los tipos europeos de entreguerras. ${ }^{12} \mathrm{Si}$ la arquitecta austriaca remite a la cocina del vagón-restaurante de los ferrocarriles como modelo de eficacia en el que inspirarse, las

12. Se trataba de una edición revisada y ampliada de un texto anterior de 1841, suscrito por Catherine en solitario y titulado Treatise on Domestic Economy (Tratado de Economía Doméstica) que había alcanzado una importante difusión y repercusión. 
estadounidenses se refieren a las pequeñas y compactas cocinas colectivas presentes en los buques de vapor de su época. ${ }^{13}$ En el levantamiento interior propuesto por Catherine Beecher se observa su temprano rechazo a una yuxtaposición de mesas y aparadores independientes para preferir en su lugar la definición de un banco de trabajo continuo -enrasado con el fregadero-, adosado a la pared y bien iluminado bajo las ventanas que en ella se abren. El espacio inferior de dicha superficie de trabajo se ocupa por contenedores para menaje y alimentos mientras que en la parte superior, entre las ventanas, se disponen unas simples estanterías y ganchos que permiten acercar todo tipo de accesorios al alcance de la mano. Por lo que respecta a su organización en planta, es posible observar cómo la autora identifica los tres vértices de lo que hoy se denomina el triángulo funcional de una cocina: el almacenamiento y conservación de alimentos (ocupado en la actualidad por el frigorífico); la limpieza y preparación (fregadero); y el cocinado-servicio (fuego). Debido a su temprana fecha no aparece todavía un dispositivo de conservación en frío sino unos contenedores para alimentos a granel (harina, aceite, azúcar,...); como tampoco cuenta con una instalación de fontanería, sino con un rudimentario sistema autónomo de agua corriente ideado por ella misma; a la vez que los fogones se apartan a un compartimento distinto, separado por puertas deslizantes, para reducir los numerosos inconvenientes producidos por un fuego todavía a partir de combustible sólido.

Volviendo a Frankfurt, cabe señalar en segundo lugar cómo en el texto anteriormente citado Grete Schütte-Lihotzky reconoce que se planteó esa disyuntiva entre una cocina-laboratorio -dedicada exclusivamente a tareas domésticas- y una cocina-comedor -más favorable a las relaciones familiares-, confesando cómo, pese a sus propias preferencias iniciales, motivos económicos decantaron finalmente la decisión hacia la opción más especializada. Sin embargo, como en el diseño de Benita Otte para la Casa Modelo, también en este caso se optó por suavizar dicha especialización comunicando directamente la estancia con el comedor adyacente «mediante una amplia puerta corredera», para mejorar la relación entre ambos espacios. Pero no es esta la única coincidencia con Bauhaus. La Cocina de Frankfurt es también un claro ejemplo de cocina integrada y compacta dispuesta en L que segrega los contenedores en dos tipos: de base y de pared. Mediante los inferiores define una superficie de trabajo continuo y sin juntas -enrasada con el fregadero y los fogones-, así como perfectamente iluminada y ventilada a través de la ventana

13. Cabe recordar que las primeras patentes de Pullman para vagón-restaurante de ferrocarril datan, precisamente, de 1869 por lo que Catherine Beecher no podía tener todavía esa experiencia. 

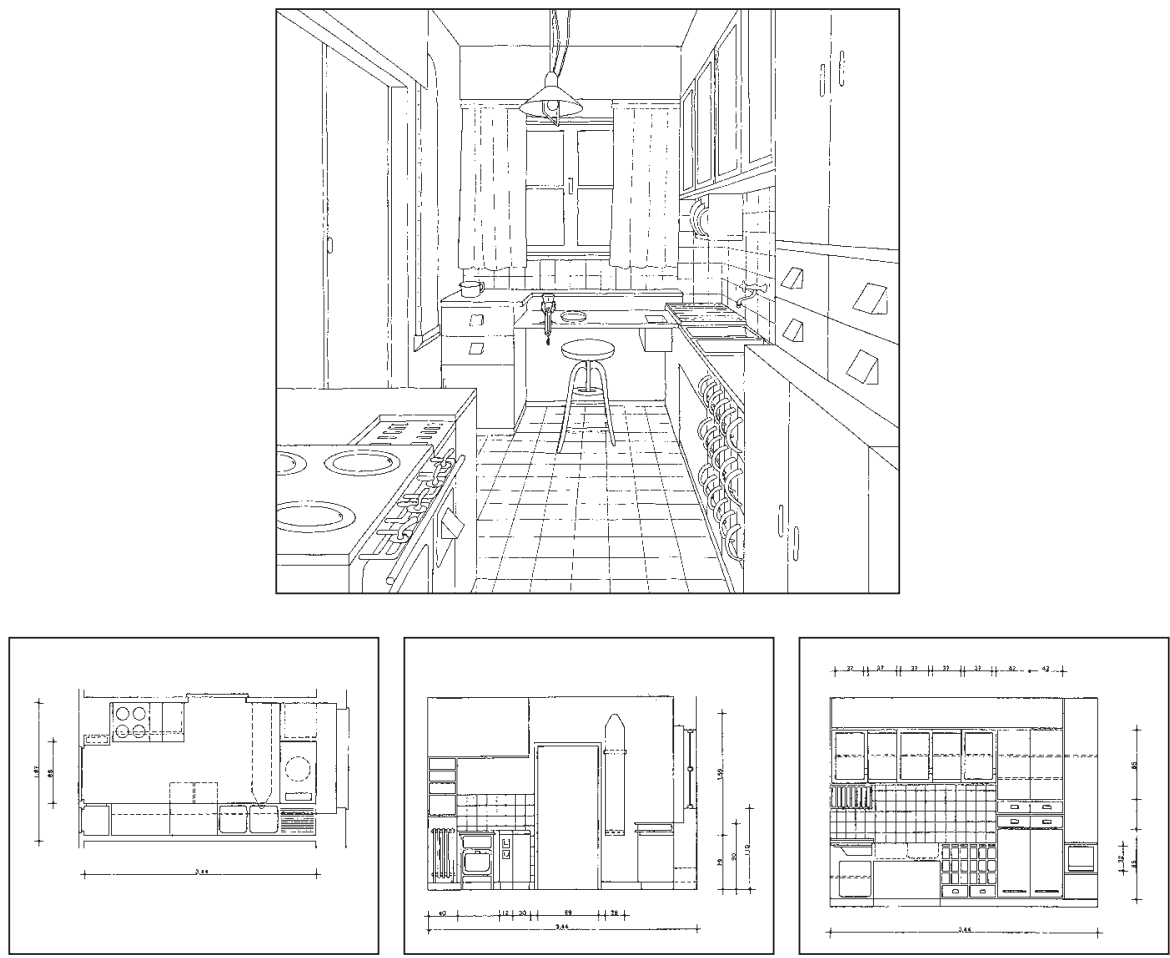

Grete SCHÜTtE-Linotzky: Cocina de Frankfurt, 1927. Vista general y planimetría.

de la estancia. Análogamente, los paramentos se revisten de aplacados cerámicos y los armarios de base carecen de patas para descansar sobre un zócalo continuo que facilita las labores de limpieza y mantenimiento. También aquí, por último, se libera parte del espacio inferior de la superficie de trabajo dejando hueco para las piernas, lo que permite sentarse para realizar parte de las tareas sacando un taburete que, cuando no se sutiliza, encaja en dicho espacio.

Sin embargo, frente al ejemplo de la Haus am Horn, incorpora nuevas aportaciones entre las que cabe destacar, en primer lugar, su ajustada superficie -inferior a los $6,50 \mathrm{~m}^{2}$ - manteniendo e incluso incrementando sus funciones, para lo que Schütte-Lihotzky se inspiró en las reducidas y compactas cocinas instaladas en los barcos y trenes de la época. En segundo lugar, sus dimensiones fueron sometidas a una estricta modulación, condición necesaria para posibilitar su estandarización y fabricación industrial masiva. Así se conseguía un ahorro económico considerable, al tiempo que se incluía su 
coste junto al de construcción de la vivienda como fórmula para hacer asequible su financiación. En palabras de la propia arquitecta:

\begin{abstract}
La cocina resultaba tan compacta que no permitía recurrir al mobiliario-tipo habitual en la época, que necesitaba mucho más espacio. La economía consecuencia del reducido tamaño de la cocina resultaba significativa, sin embargo, la Cocina de Frankfurt proporcionaba la doble ventaja de simplificar el trabajo de sus usuarios. Únicamente recurriendo a tales argumentos fue posible obtener el permiso de las autoridades municipales de Frankfurt para la instalación de las cocinas, con todas sus aplicaciones destinadas a la simplificación de tareas [...] Los costos de la unidad completa se sumaban al presupuesto de construcción y se incluían en el alquiler, una solución aceptable para los inquilinos porque ya no necesitaban amueblar la cocina. Sobre este principio financiero fue posible la producción masiva de la Cocina de Frankfurt, ahorrando a miles de mujeres gran cantidad de tiempo y esfuerzo en beneficio de sus familias y de su propia salud. ${ }^{14}$
\end{abstract}

Además, se estudiaron minuciosamente todas las actividades a ejecutar, integrando nuevos accesorios tales como: una tabla de planchar abatible que se recogía sobre la propia pared; un canal de residuos junto a la superficie de trabajo que podía vaciarse al exterior a través de un colector vertical; un contenedor de columna para escobas, cubos y productos de limpieza; una despensa que incorporaba los vertedores Haarer de aluminio para conservar alimentos a granel, ${ }^{15}$ excepto en el caso de la harina, almacenada en un contenedor especial fabricado en madera de roble cuyo ácido tánico impide que se agusane; un escurreplatos sobre el fregadero para evitar secar la vajilla; un radiador para el necesario confort térmico; una luminaria corredera que permite concentrar la luz allí donde más falta haga en cada momento; etc. Asimismo, la posición de cada uno de estos elementos fue estudiada en relación a todos los demás para ahorrar todo esfuerzo innecesario al tiempo que se procura la máxima comodidad de trabajo.

Una cocina tan austera y racionalizada resultaba tan innovadora frente a los tipos acostumbrados en la época que, en 1928, Paul Wolff filmó una película muda promocional, de 7,53 minutos de duración, ${ }^{16}$ con el objetivo de facilitar su difusión y aceptación social. Para ilustrar la enorme simplificación de tareas que procuraba el nuevo diseño, la película muestra una comparación

14. Grete SchütTE-LiHotzKy: Op. cit.

15. Patentados por el ingeniero Otto Haarer en 1923, reunían las ventajas de un cajón y de una lata con un resultado higiénico y muy práctico.

16. Véase <http://www.vam.ac.uk/vastatic/microsites/1331_modernism/highlights_18_v02. html>, consultada el 06-12-2010, trabajo incluido en la exposición Modernism: Designing a new world 1914-1939, celebrada en el Victoria \& Albert Museum de Londres entre el 6 de abril y el 23 de julio de 2006. 
entre el trabajo de un ama de casa en la cocina de Frankfurt con su equivalente en una cocina convencional de esos años. De esa manera destaca la funcionalidad de muchas de las nuevas soluciones anteriormente apuntadas para terminar con unos diagramas comparativos en planta donde se señala la diferencia entre la distancia recorrida por el ama de casa en la cocina tradicional durante la realización de sus tareas habituales -unos 90 metros-, frente a su equivalente en la Cocina de Frankfurt -de tan solo 8 metros-, como demostración científica definitiva de la mayor eficacia del diseño de esta última.

Las revisiones críticas a la propuesta de Grete Schütte-Lihotzky aparecerán desde fechas muy tempranas precisamente a partir de esa discusión entre ambas alternativas, cocina-laboratorio y cocina-comedor, que permanecerá en el debate arquitectónico contemporáneo a finales de los años veinte y principios de los treinta. Aunque, como ya se ha visto, la solución de Frankfurt se impondrá de manera mayoritaria por motivos económicos, es

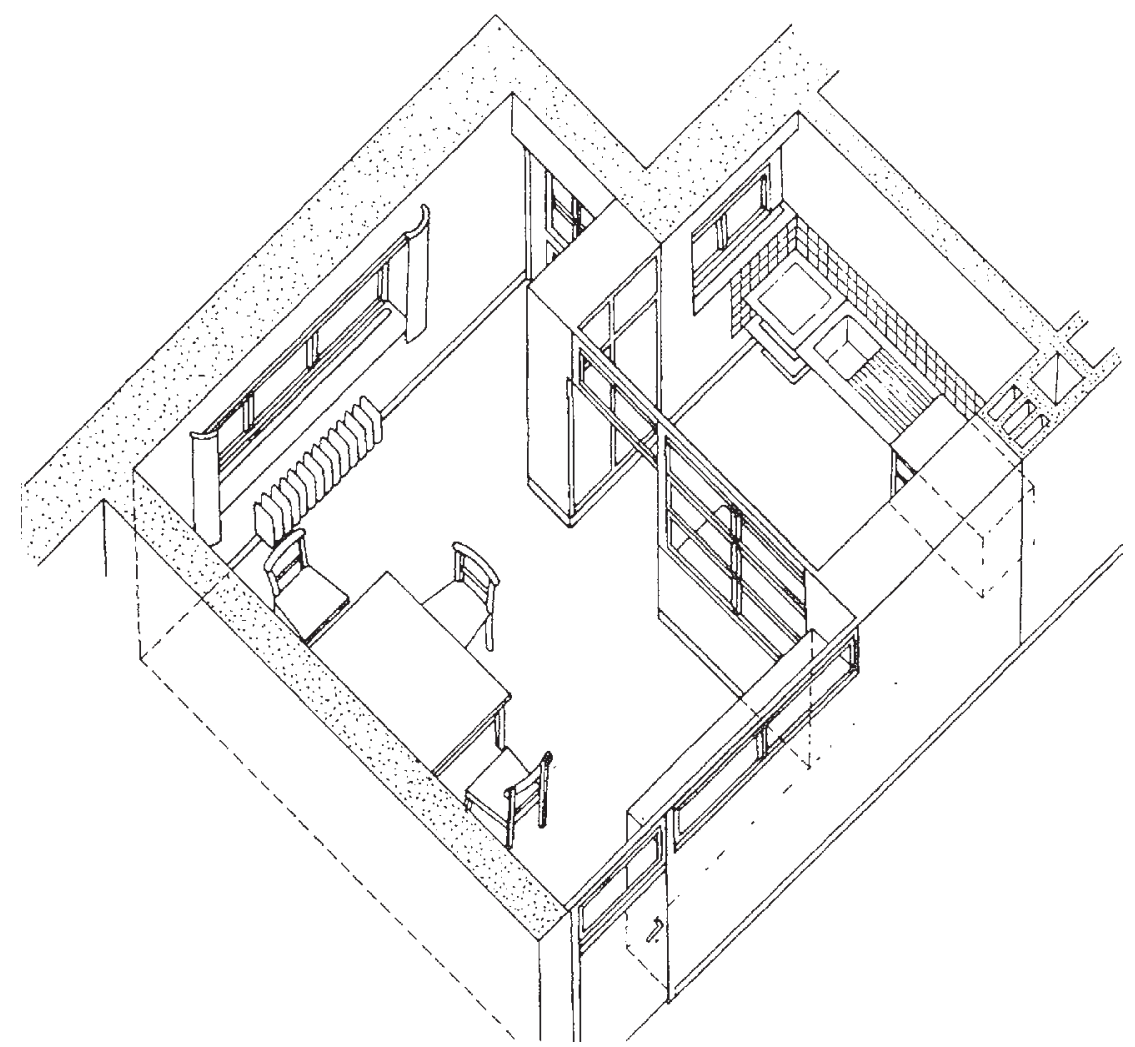

Robert VolHoelzer, Walther SCHMidt y Hanna Löw: Cocina de Munich, 1928-29. 


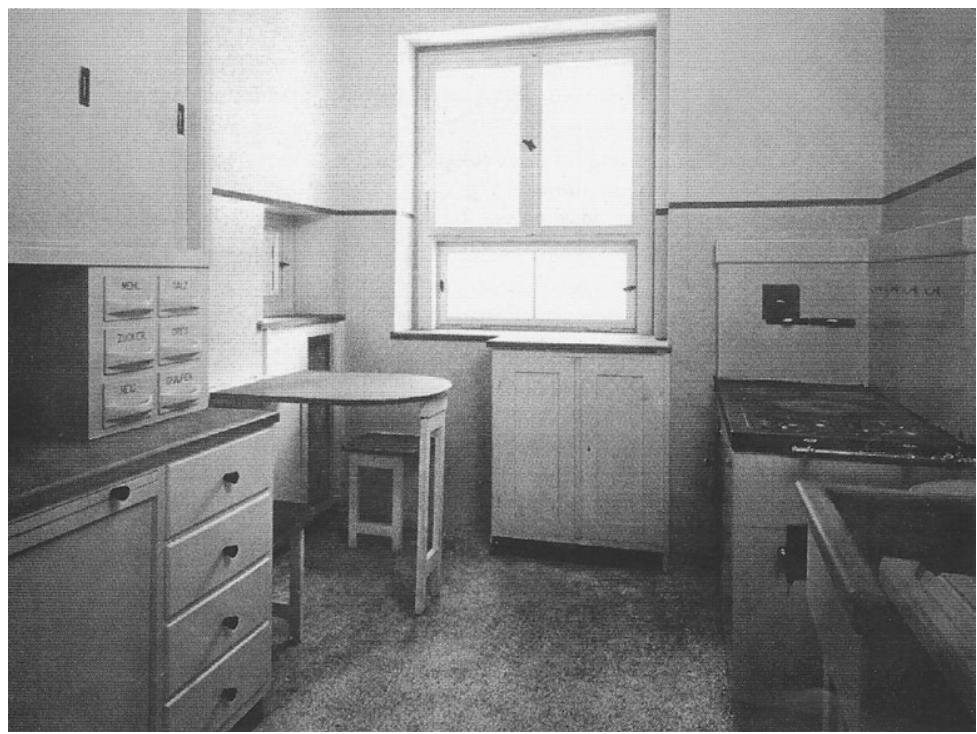

Bruno TAUT: Vivienda social, Onkel Toms Hütte, Berlín, 1927-32. Vista de una cocina.

posible encontrar otras propuestas interesantes que ensayarán diferentes grados de permeabilidad entre esa cocina especializada en las tareas domésticas y el comedor adjunto donde tienen lugar las actividades familiares colectivas. Tales son los casos, por ejemplo, de la conocida como Cocina de Munich, ${ }^{17}$ que se encuentra en las construcciones de Robert Vorhoelzer y Walther Schmidt -con el asesoramiento de la arquitecta Hanna Löw- en 1928; o de las cocinas instaladas en las viviendas de Onkel Toms Hütte por Bruno Taut (Berlín, 1927). ${ }^{18}$ En el ejemplo de Munich se establece una comunicación visual entre cocina y salón-comedor mediante una puerta y una amplia vidriera que mitiga el aislamiento de quien realiza las tareas domésticas. Bruno Taut, por su parte, ensaya también diferentes soluciones para comunicar cocina y comedor tanto para facilitar el servicio de comedor como para comunicar acústica y visualmente ambos espacios, al tiempo que incorpora -aunque sea plegable o de mínimas dimensiones- una mesa o una barra donde realizar pequeñas colaciones o bien, donde mantener la atención sobre las tareas infantiles sin abandonar las ocupaciones domésticas.

17. Véase Otl AICHER: La cocina para cocinar. El final de una doctrina arquitectónica. Barcelona: Gustavo Gili, 2004, p. 20.

18. Véase Rita MielKe: op. cit., p. 20. 


\section{Propuestas de cocina colectivizada ¿única alternativa auténticamente feminista?}

No cabe duda de que todos los ejemplos reseñados supusieron importantes avances en las determinaciones de la cocina contemporánea como espacio principal de una nueva vivienda que, merced a la incorporación de innovaciones fundamentales en los ámbitos constructivo, funcional y formal, permitió una notable reducción presupuestaria. De esta manera se posibilitó, por primera vez, el acceso a una vivienda digna de amplios sectores de la población que, hasta esas fechas, habían permanecido excluidos de tal derecho. Al mismo tiempo, gracias a la incorporación de estándares mínimos de confort: generalizando instalaciones de fontanería y saneamiento o de abastecimiento energético; renovando el equipamiento doméstico - no sólo de cocinas y baños-; ensayando nuevas tipologías de vivienda más adecuadas a los usuarios a los que estaban destinadas; racionalizando la organización de las tareas domésticas; garantizando condiciones higiénicas de soleamiento y ventilación; etc. contribuyeron a simplificar las tareas domésticas de innumerables amas de casa, de manera que facilitaron su integración en un mercado laboral industrial generalmente siempre favorable a la incorporación de mano de obra barata y de escasa especialización.

Bien es cierto que todos los ejemplos mencionados apenas se cuestionaban el rol social de la mujer a quien continuaban atribuyendo, prácticamente en exclusiva, la responsabilidad en las tareas domésticas y en el cuidado de los niños. Catherine Beecher, por ejemplo, concibió su obra como libro de texto para «escuelas femeninas», así como parte de la obra de Christine Frederick fue publicada en forma de curso por correspondencia para que las amas de casa estadounidenses mejoraran su rendimiento en la realización de las tareas diarias. Por su parte, la distribución de la Haus am Horn consagraba los roles sociales de género, incluyendo dormitorios separados para el matrimonio de manera que el femenino comunicaba directamente con el cuarto infantil mientras que el masculino se encontraba en otra de las alas y directamente relacionado con el pequeño despacho abierto al salón central. Igualmente, es una mujer la única e indudable protagonista de esa breve película anteriormente reseñada que demuestra las ventajas de la Cocina de Frankfurt, ilustrando su funcionamiento.

Todas estas razones permiten argumentar cómo ese indudable protagonismo de numerosas mujeres -puesto en evidencia a lo largo del presente texto-, en la definición y desarrollo del tipo de cocina contemporánea apenas puede explicarse sin atribuirlo a una «concesión» de sus colegas masculinos que únicamente buscaron su colaboración para el diseño de aquellos espacios 
o equipamientos tradicionalmente considerados como femeninos, en los que les reconocían superior competencia. Tales fueron los casos de Benita Otte para la Bauhaus en 1923, de Grete Schütte-Lihotzky con Ernst May en Frankfurt o de Erna Meyer en la Weissenhof de Stuttgart de 1927. Sin embargo, resulta asimismo innegable que la contribución de estas brillantes profesionales pioneras en la transformación de la cocina doméstica, en sentido de su racionalidad, mecanización y modernización, permitió abrir las primeras grietas que aceleraron la salida de la mujer de ese mismo espacio interior -privado- en el que había permanecido recluida durante tanto tiempo, facilitando su gradual incorporación al espacio exterior -público-, impulsando así un imparable proceso de conquista de su progresiva igualdad social.

Sin embargo, en paralelo al desarrollo explicado con anterioridad, se planteó una alternativa diferente que sí se cuestionó e intentó transformar radicalmente el papel social de la mujer, liberándola de las tareas domésticas. Se trata de las numerosas iniciativas tendentes a eliminar las cocinas en las viviendas particulares para sustituirlas por la gestión comunitaria y centralizada de la manutención familiar, así como de otras pesadas tareas domésticas tales como la lavandería o, incluso, la limpieza. La idea no era nueva dado que, sin necesidad de remontarse a casos singulares de la Antigüedad clásica, ${ }^{19}$ los teóricos del socialismo utópico ya habían planteado, durante la Ilustración, la creación de comunas autogestionadas en régimen cooperativo. Los Falansterios de Charles Fourier (1772-1837), por ejemplo, eran comunidades compuestas de residencias y servicios colectivos donde las viviendas carecían por completo de cocina puesto que la manutención general se encontraba centralizada en una cantina. Es conocido cómo la idea de Fourier fue llevada a la práctica, entre otros, por el industrial Jean-Baptiste Godin (1817-1888), fabricante de hornos y fogones, quien en 1865 construyó una versión industrial y reducida, denominada Familisterio, constituida por un conjunto de viviendas servidas desde una cocina comunitaria.

Poco después, hacia finales del siglo XIX e inspirándose en el movimiento de las Ciudades-Jardín impulsado por Ebenezer Howard (1850-1920), se construyeron en Inglaterra diferentes colonias como el complejo Meadow Way Green (Letchworth, 1914) cuyos inquilinos se encargaban colectivamente de la planificación del menú semanal y del abastecimiento de alimentos, mientras que unas cocineras a sueldo se responsabilizaban de las tareas culinarias, de acuerdo con un sistema que permaneció vigente hasta $1970 .{ }^{20}$ Aunque

19. ARISTÓFANES: Asambleístas, 392 a. n. e.

20. Véase Rita MiElKE: op. cit., p. 21. Sobre la ideología colectivista del movimiento de Ciudad Jardín puede verse también, por ejemplo, Raymond Unwin: La práctica del 
tales iniciativas fueron objeto de constantes críticas por parte de la burguesía, que las interpretaba como una firme amenaza a la familia y al matrimonio como pilares de la sociedad, con anterioridad a la Primera Guerra Mundial, la iniciativa fue imitada en otros lugares de Europa como Copenhague, Berlín o Viena, llegando a tener numerosos defensores y adeptos incluso en Estados Unidos, ${ }^{21}$ antes de descartarse finalmente en aras de la consolidación del sistema capitalista:

Algunas feministas y teóricas del pensamiento doméstico progresista predijeron la centralización de las principales tareas domésticas a través del establecimiento de servicios comunitarios. Basándose en el precedente de los trenes, barcos y hoteles de lujo, los reformadores vieron la posibilidad de realizar las tareas domésticas a escala industrial. Sin embargo, después de la Primera Guerra Mundial, se reafirmó como norma norteamericana el modelo privado de llevar la casa. Muchos líderes políticos y empresariales querían evitar que las mujeres compitieran con los hombres por salarios, sobre todo con los veteranos de guerra que volvían a casa. La propiedad de la vivienda privada se vio como una forma de asegurar que los trabajadores estuvieran contentos, cargados de hipotecas y por tanto a prueba de huelgas, mientras que al mismo tiempo se incrementaría la base de consumidores para los bienes producidos en serie. ${ }^{22}$

Sin embargo, el lugar donde esta iniciativa tuvo una mayor repercusión fue, evidentemente, en Rusia durante los años de fervor revolucionario posteriores a octubre de 1917. En esos primeros momentos, las comunas se organizaron de manera casi espontánea a partir de los repartos de viviendas burguesas:

La mudanza masiva de obreros a las casas de la burguesía transcurría paralelamente al proceso de surgimiento natural de las comunas domésticas [...] Al recibir gratuitamente una vivienda en usufructo, los obreros creaban en los edificios órganos de autoadministración, los cuales no sólo administraban la explotación del edificio, sino que también organizaban tales instituciones comunales domésticas como comedores-cocinas comunes, jardines de infancia, casas-cuna, rincones rojos, bibliotecas y salas de lectura, lavanderías, etc. La manutención de estas instituciones, así como la limpieza y la reparación de las instituciones de uso común, eran realizadas por los mismos moradores, sin remuneración. ${ }^{23}$

Urbanismo. Una introducción al arte de proyectar ciudades y barrios. Barcelona: Gustavo Gili, 1984, pp. 281-283.

21. Sobre las experiencias colectivistas en EUA, véase el magnífico trabajo de Dolores HAYDEN: The Grand Domestic Revolution. Cambridge: MIT Press, 1982.

22. Ellen LUPTON y J. ABBOtT MilleR: El cuarto de baño, la cocina y la estética de los desperdicios. Procesos de eliminación. Madrid: Ayuntamiento de Madrid, 1992, p. 12.

23. Selim Omárovich JAN-MAGOMÉDOv: Las cien mejores obras del vanguardismo soviético (ed. bilingüe). Moscú: URSS, 2004, p. 107. 
Estas uniones voluntarias de consumo estaban regidas por un Estatuto que reglamentaba la vida en la comuna, velaba por el mantenimiento, socializaba la alimentación y el cuidado de los niños y, ocasionalmente, alcanzaba hasta la gestión de los recursos financieros. De esa manera se contribuía a la liberación de la mujer de las tareas domésticas tradicionales con el objetivo de incorporarlas a la vida social y, sobre todo, al sistema productivo, llevando a la práctica las ideas enunciadas por el propio Lenin: «Crearemos instituciones modelos, cantinas, guarderías que libren a la mujer de las preocupaciones domésticas...». ${ }^{24}$

En una segunda etapa, a partir de 1925, aparecieron los primeros proyectos de instalaciones colectivizadas ocupando edificaciones específicas de nueva planta: cocinas industriales, viviendas comunales, clubes obreros, etc. Según Jan-Magomédov: «el camino principal en la solución del problema social de liberar a la mujer de la carga doméstica se veía en el máximo desarrollo de la red de alimentación social, próxima no sólo al sitio de trabajo, sino también a la vivienda.». En esa dirección, la primera cocina industrial de Rusia se abrió ese año en la ciudad de Ivánovo-Voznesiensk, núcleo industrial textil situado en el centro de la Rusia europea, convirtiéndose en el prototipo de la nueva tipología edificatoria. ${ }^{25}$

Por su parte, el ejemplo más conocido de vivienda comunal es posiblemente el Edificio de viviendas en el Bulevar Novinski (Narkomfin), levantado en Muscú por Moisei Guínzburg e Ignaty Milinis entre 1928-30. Inicialmente se proyectó como un conjunto de cuatro bloques: vivienda, servicios comunes (sala deportiva y cocina-comedor), jardín de infancia independiente y patio de servicios (equipado con lavandería industrial y garaje). Finalmente sin embargo, sólo se ejecutó el de viviendas y, parcialmente, el de servicios donde se encuentra la cocina -que distribuía la alimentación por las distintas viviendas- y un jardín de infancia. El bloque de vivienda tiene seis plantas elevadas sobre pilotis y distribuidas por dos corredores -en planta segunda y sexta-, de manera que el ubicado en planta segunda comunica directamente con el bloque comunal de servicios. Las viviendas corresponden a los tipos desarrollados por el Departamento de Estandarización del Stroikom de la RSFR. ${ }^{26}$

24. LENIN en la cuarta conferencia de los trabajadores moscovitas sin partido, 1919, cit. en Anatole KopP: Arquitectura y urbanismo soviéticos de los años veinte. Barcelona: Lumen, 1974 , p. 133.

25. V. Selim O. JAN-MAGOMÉDOv: op. cit., p. 137-138.

26. Comité para la edificación de la República socialista federativa soviética de Rusia, del que formaban parte M. Barsch, V. Vladímirov, A. Pasternak y G. Sum-Shik, bajo la dirección de M. Guínzburg. 

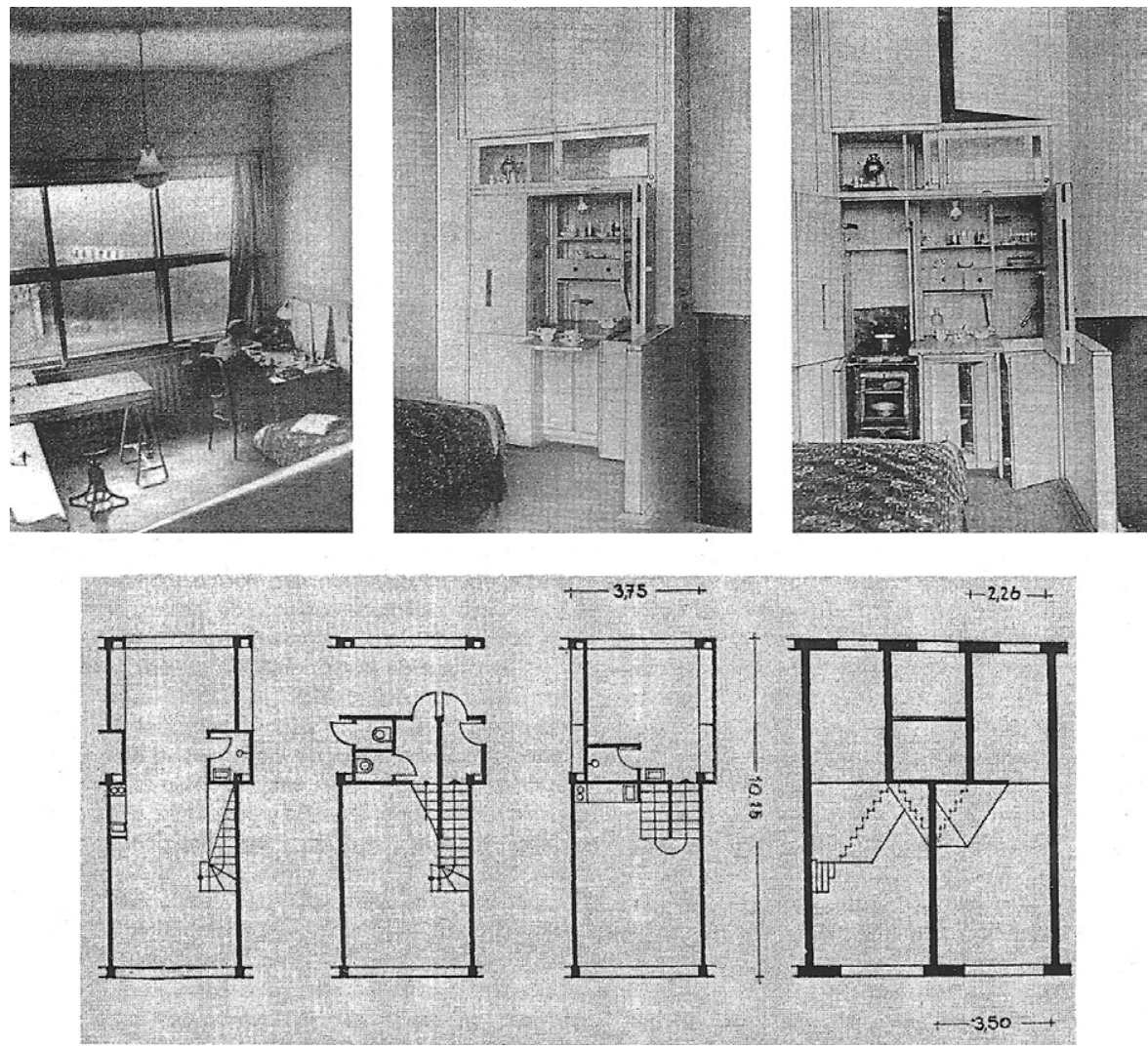

Moisei GuínZBurg e Ignaty MiLINIS: Vivienda comunal (Narkomfin), Moscú, 1928-30. Planta vivienda tipo y equipamiento de una cocina.

Se trata de viviendas transitorias, esto es, donde además de las instalaciones comunales de uso colectivo, cada familia cuenta todavía con un apartamento propio, si bien, de superficie reducida. Se idearon tres variantes de 27,30 y 31 $\mathrm{m}^{2}$, cada uno de los cuales consta de recibidor con escalera que -bien hacia arriba, bien hacia abajo- conduce hasta el espacio principal de 3,5 m (3,2 m) de altura. Junto a la ventana se sitúa un equipo básico de cocina -hornilla, fregadero,...-, que puede cerrarse mediante unas puertas correderas. En la parte posterior de menor altura, 2,25 $\mathrm{m}(2,15 \mathrm{~m})$, aparece un dormitorio y un baño con bañera, ducha o, simplemente lavabo. Cada unidad constituye un apartamento de un dormitorio o dormitorio y medio, destinado a una familia de tres o cuatro miembros. 
El Lissitzky, junto con sus estudiantes del VJUTEIN, ${ }^{27}$ diseñó prototipos de mobiliario parcialmente empotrado para estas unidades, distinguiendo zona de trabajo, zona de comedor y zona de dormitorio; por su parte, S. Lisagor desarrolló diferentes instalaciones empotradas (guardarropas, anaqueles, cocina-armario,...) que llegaron a producirse para el equipamiento de varios tipos experimentales construidos en el bulevar Gogol de Moscú. ${ }^{28}$

Todas estas interesantes investigaciones perecerían, sin embargo, en breve plazo víctimas, en parte, de sus propios excesos tras cubrir en pocos años el tramo que separa unos planteamientos razonables de una utopía colectivista deshumanizadora. La puesta en marcha del Primer Plan Quinquenal, a partir de 1929, exigía abundante mano de obra de manera que, a principios de los treinta, se volvió indispensable la incorporación masiva de la mujer al proceso productivo lo que, inmediatamente, agudizó el problema de la vivienda a la vez que aceleró la transformación de los modos de vida. En ese contexto cabe entender, por ejemplo, la propuesta de N. Kuzmín que, en 1928-29, planteó un Combinado habitacional-Poblado para los mineros de la región hullera de Anzherka-Sudzhenka, calculado para más de cinco mil personas organizadas por grupos de edad que podían relacionarse entre sí pero cuyos dormitorios estaban separados. El proyecto reglamentaba todos los aspectos de la vida de los mineros, incluyendo un "gráfico de vida» que contemplaba todas las etapas de la vida de un comunero desde su nacimiento hasta su muerte.

Todo está colectivizado, empezando por el cosido de los botones y el arreglo de la ropa (la esposa no tiene tiempo para eso), y culminando con la limpieza de las habitaciones. Los trabajadores se levantan después de dormir y salen de sus dormitorios. Las camas se pliegan. Un personal especializado realiza la limpieza de las habitaciones... El área de los dormitorios se calculó partiendo del gráfico de movimiento y del mobiliario de las habitaciones. El mobiliario era el siguiente: camas plegables de pared, mesita de noche y armario para las batas. El gráfico de movimiento era: el obrero se levanta (al llamado de la radio que regula la vida de la comunidad), guarda la cama, se dirige a su armario, se pone la bata y el calzado y sale al cuarto de gimnasia donde puede hacer ejercicios, tomar una ducha, lavarse y vestir la ropa limpia preparada con antelación por el personal especializado. ${ }^{29}$

27. Acrónimo de «Instituto Superior del Arte y de la Técnica», nueva denominación entre 1927-30 de los VJUTEMAS, «Talleres de Enseñanza Superior del Arte y de la Técnica» (1920-27), escuela vanguardista soviética radicada en Moscú, con interesantes paralelismos con la Bauhaus alemana.

28. V. Selim O. JAN-MAGÓMEDOV: op. cit., p. 321-324.

29. N. KuzMín: «Problema de la organización científica del modo de vida», en AM (Arquitectura Moderna), n. ${ }^{\circ}$ 3, 1930, pp. 16-17, cit. en Selim O. JAN-MAGÓMEDOv: op. cit., p. 332. 
El proyecto fue defendido por Kuzmín en 1929 ante los propios mineros, quienes le dieron su aprobación lo que llevó a la empresa minera responsable a firmar un contrato con el arquitecto para preparar la construcción del complejo. Sin embargo, después del decreto del Comité Central del Partido Comunista, de 1930, «Sobre la reorganización del modo de vida», los trabajos fueron definitivamente suspendidos.

De esta manera, esos planteamientos razonables denominados transitorios -como el comentado Narkomfin-, donde las viviendas todavía eran completas y la colectivización preservaba una cierta intimidad del grupo familiar, evolucionaron hacia una progresiva reducción del espacio de uso individual, considerando como colectivas funciones originalmente concebidas como familiares, hasta alcanzar excesos casi cuartelarios -como el de Kuzmín-, donde desaparecía el grupo familiar y el individuo se disolvía en el grupo al estar obligados todos sus usuarios a realizar, a la vez, las mismas actividades durante todo el día y durante toda su vida. En palabras de Anatole Kopp:

No deja de ser verdad que en el campo de la vivienda los errores se pagan caros y que si se hubiera dado prioridad a las soluciones del Stroikom, esas viviendas serían hoy usadas por los solteros, los ancianos y los matrimonios de un solo hijo, que constituyen una parte importante de la población. ${ }^{30}$

A todo ello cabe añadir que durante la década de los treinta, como consecuencia del aludido decreto y de la agudización de la carestía de viviendas, numerosas de esas células mínimas, originalmente planificadas y dimensionadas para grupos de tres o cuatro miembros, fueron ocupadas por varias familias lo que las hizo verdaderamente más incómodas que las viviendas convencionales, donde cada familia mantenía cierta independencia al ocupar un dormitorio. Circunstancias que derivaron en una clara reacción popular en contra de ese tipo de residencias.

\section{Difusión y crisis del tipo tras la Segunda Guerra Mundial}

Al mismo tiempo, el tipo establecido por Grete Schütte-Lihotzky inició en occidente su desarrollo hacia la producción industrializada, de la mano de emprendedoras empresas que empezaron a experimentar con nuevos tipos de contenedores cada vez más especializados o con nuevos materiales sintéticos mejor adaptados a los exigentes requisitos de su función específica. Comenzaba así una carrera pronto interrumpida por el estallido de la Segunda Guerra Mundial que reclamaría para la causa bélica la práctica exclusividad de los esfuerzos financieros e industriales.

30. A. KopP: op. cit., p. 170-171.

Feminismo/s 17, junio 2011, pp. 183-211 
Durante los años de la contienda, la Cocina de Frankfurt continuaría su periplo por Estados Unidos y Suecia, territorios periféricos del conflicto bélico. Los diseñadores estadounidenses del período aerodinámico aportaron la mecanización de algunos elementos de la nueva cocina, siendo responsables de la incorporación a la misma de numerosas innovaciones tecnológicas, al definir las características de muchos dispositivos progresivamente convertidos en imprescindibles merced al impulso de poderosas estrategias de mercado. ${ }^{31}$ Los del país nórdico, por su parte, aportaron la humanización característica del diseño escandinavo, suavizando ese funcionalismo tan austero que había tenido su origen en los países centroeuropeos. Ello permitió que, a principios de los cincuenta, cuando los años más duros de posguerra estaban quedando definitivamente atrás, el modelo de cocina compacta e integrada fuera adoptado de manera mayoritaria -bajo la denominación de «cocina sueca»-, aprovechando el masivo proceso de reconstrucción de los hogares europeos e incorporando numerosos electrodomésticos nuevos, buena parte de los cuales habían definido su moderno y flamante diseño prototípico de la mano de los profesionales estadounidenses del Streamlining.

En ese contexto, por ejemplo, la empresa alemana Poggenpohl lanzó al mercado su primera cocina integrada en 1950, con una distribución modular y flexible de contenedores murales y de base que permitían equipar la estancia de pared a pared, solución que a lo largo de la década fue adaptándose para integrar no solo el fregadero, sino también los electrodomésticos que no dejarán de ir apareciendo y evolucionando con el tiempo: fogones eléctricos, frigorífico, horno, lavadora, lavavajillas, microondas, etc. La capacidad combinatoria del equipamiento y de los contenedores de la cocina vino a consagrarse de manera definitiva en 1957, gracias a la publicación de las primeras normas DIN relativas a este espacio.

A partir de esos momentos, la cocina doméstica quedaría sometida a los vaivenes de un consumo regido por las reglas de la publicidad y del mercado, de modo que, una vez en este punto, cabe preguntarse por la vigencia del tipo cuya evolución ha sido descrita, en unas condiciones que tanto difieren de aquéllas para las que tuvo lugar su definición. En la actual sociedad del bienestar, la incorporación de la mujer a la vida pública es ya un hecho incuestionable que, hoy por hoy, ha desplazado el debate social más hacia la corresponsabilidad en las tareas domésticas, desde la limpieza, la compra o la

31. Sobre la mecanización del espacio doméstico por parte de la industria estadounidense y su influencia en la definición de la identidad femenina, puede verse Ellen LUPTON: Mechanical Brides. Women and Machines from Home to Office. Nueva York: Cooper-Hewitt National Museum of Design-Smithsonian Institution-Princeton University Press, 1993. 
cocina hasta la atención infantil. Por otro lado, aún subsistiendo el problema de la vivienda, tiene también un cariz bien distinto. Pese a las dificultades ciertas que determinados sectores sociales tienen para acceder a la misma, como consecuencia en buena medida de su elevado precio derivado de las condiciones de mercado, el derecho a la vivienda está asumido por la legislación de la mayoría de los países occidentales. Del mismo modo, su construcción ha sido sometida a normativas que regulan desde sus dimensiones hasta sus condiciones de habitabilidad o calidad constructiva, especificando, entre otras características, los mínimos de ventilación, iluminación, aislamiento o equipamiento. Como resultado, el mayor problema actual radica, probablemente, en que lo estricto y sobreabundante de tales regulaciones convierte, en numerosas ocasiones, en norma incuestionable los mínimos que ellas establecen. Por último, tampoco el acceso a una alimentación de subsistencia suele representar hoy día un problema grave para la mayoría de la población en el denominado primer mundo, por apuntar únicamente algunos de los principales agentes que, en su momento, actuaron como impulsores de los cambios relatados.

Reunirse a comer en las poblaciones del mundo contemporáneo suele ser un acto cargado de elevado contenido social. Compartir un almuerzo o una cena con amigos, compañeros de trabajo o, incluso con clientes o colegas de negocio o profesión, acostumbra ser pretexto habitual no tanto para alimentar el cuerpo sino para fomentar y cultivar las relaciones personales en un ambiente agradable y distendido. Tal dimensión social no debería corresponder únicamente a la función de comer. Por el contrario, también la de cocinar, junto con el resto de tareas que ello conlleva -aprovisionamiento, mantenimiento, preparación, limpieza,...-, debería tener un contenido social análogo. Como señala Otl Aicher, tanto comer como cocinar son actividades mucho más agradables cuando se llevan a cabo en compañía:

Cocinar es una actividad de varios. En la cocina, el ser humano es un ser social. La cocina es una función de la naturaleza social del hombre. Sólo se cocina con ganas cuando se va a disfrutar de la cocina con otros. Y se cocina con más ganas si se cocina en compañía.

Por muy sociales que hayan sido las preocupaciones de los arquitectos que concibieron la Cocina de Frankfurt, forzar a alguien a cocinar donde sólo cabe una persona, es parecido a una condena. ${ }^{32}$

Cabría aventurar por tanto para terminar que, respecto a su futuro como espacio doméstico, la cocina no solo debería ser el lugar donde compartir buena

32. Otl Aicher: Op. cit., p. 43.

Feminismo/s 17, junio 2011, pp. 183-211 
parte de esas tareas que giran alrededor de la función de cocinar sino también, deseablemente, las relativas a la de comer. Con ello se amplificaría otro de sus papeles fundamentales al definirse como un lugar central en la vivienda para la socialización y educación de las nuevas generaciones donde, de manera natural, éstas puedan aprender el valor y la satisfacción de responsabilizarse y compartir las diferentes tareas domésticas. He ahí, probablemente, uno de los mayores retos que se presenta a los jóvenes profesionales de la arquitectura y el diseño a la hora de interpretar las características de las sociedades postindustriales donde desarrollarán su trabajo. Para ellos quizás resulte positivo recordar, por último, el mito moderno de la fusión entre arte y vida, según el cual la arquitectura -y, por ende el diseño- no solo reflejan una imagen del mundo en el que desarrollan su actividad sino que, mediante ésta, son también capaces de incidir en la transformación de la sociedad, de sus grados y valores internos, al dar forma a sus funciones.

\section{Referencias bibliográficas:}

AICHER, Otl: La cocina para cocinar. El final de una doctrina arquitectónica. Barcelona: Gustavo Gili, 2004 (ed. orig.: Munich, 1982).

AtTFIELD, Judy: «Form/female follows Function/male: Feminist Critiques of Design», pp. 199-225, en John A. WALKER: Design history and the history of design. Chicago: Pluto Press, 1989.

BAUMHOFF, Anja: «Las mujeres en la Bauhaus: un mito de la emancipación», pp. 96-107, en Jeannine Fiedler y Peter FeIERABend (eds.): Bauhaus. Madrid: Könemann, 2000 (ed. orig.: Colonia, 1999).

CAMPí I VALLS, Isabel: «Algunas reflexiones sobre la historia del diseño de productos», pp. 219-241, en La idea y la materia, V. I: El diseño de producto en sus orígenes. Barcelona: Gustavo Gili, 2007.

DROSDE, Magdalena: Bauhaus, 1919-1933. Colonia: Taschen, 1991.

ESPEGEL Alonso, Carmen: Heroinas del espacio: mujeres arquitectos en el movimiento moderno. Buenos Aires: Atlántida, Nobuko, 2007.

GIEDION, Sigfried: La mecanización toma el mando. Barcelona: Gustavo Gili, 1978 (ed. orig.: Nueva York, 1948).

HAYDEN, Dolores: The Grand Domestic Revolution. Cambridge: MIT Press, 1982

JAN-MAGOMÉDOV, Selim Omárovich: Las cien mejores obras del vanguardismo arquitectónico soviético (ed. bilingüe). Moscú: URSS, 2004.

KopP, Anatole: Arquitectura y urbanismo soviéticos de los años veinte. Barcelona: Lumen, 1974 (ed. orig.: París, 1967).

LuPTON, Ellen: Mechanical Brides. Women and Machines from Home to Office. Nueva York: Cooper-Hewitt National Museum of Design-Smithsonian Institution-Princeton University Press, 1993. 
J. AbBott Miller: El cuarto de baño, la cocina y la estética de los desperdicios. Procesos de eliminación. Madrid: Ayuntamiento de Madrid, 1992 (ed. orig.: Nueva York, 1992).

Mielke, Rita: La cocina. Historia, cultura, diseño. Berlín: Feierabend, 2004.

OEDEKOVEN-GERISCHER, Angela et al. (eds.): Frauen im Design: Berufsbilder und Lebenswege seit 1900. Women in Design: Careers and Life Histories since 1900 (2 v.) Stuttgart: Design Center Stuttgart, 1989.

SCHÜTTE-LihotZKY, Grete: Erinnerungen (Memorias). Viena: manuscrito inédito, 1980-90. Citado en la web del Museo Austriaco de Artes Aplicadas y Arte Contemporáneo (MAT), <http://www.mak.at/e/sammlung/studien/studiens_ frakue_e.html>, consultada el 06-12-2010.

VALDIVIESO, Mercedes: «Retrato de grupo con una dama: el papel de la mujer en la Bauhaus», pp. 246-255, en Anna CALvera y Miquel MAllol (eds.): Historiar desde la periferia: historia e historias del diseño. Barcelona: Universitat de Barcelona, 2001.

- «La aportación de la Bauhaus a la innovación del espacio doméstico: la «Casa Modelo» Haus am Horn (1923)», <http://www.ub.edu/gracmon/capapers/ mercedesvaldivieso.pdf $>$, consultado el 05-12-2010.

WeITZ, Eric D.: La Alemania de Weimar. Presagio y tragedia. Madrid: Turner, 2009 (Ed. orig.: Princeton University Press, 2007).

WOLF, Paul: Frankfurter Küche, película promocional de 7'53" incluida en la exposición Modernism: Designing a new world 1914-1939, celebrada en el Victoria \& Albert Museum de Londres entre el 6-04 y el 23-07-2006, consultado el 06-12-2010, <http://www.vam.ac.uk/vastatic/microsites/1331_modernism/ highlights_18_v02.html>. 